\title{
CONHECIMENTOS E DIFICULDADES MANIFESTADOS POR ALUNOS DA ENGENHARIA CIVIL EM UMA AVALIAÇÃO DIAGNÓSTICA DE ESTATÍSTICA
}

\author{
KNOWLEDGE AND DIFFICULTIES EXPRESSED BY CIVIL ENGINEERING \\ STUDENTS IN A DIAGNOSTIC EVALUATION OF STATISTICS
}

Manoel dos Santos Costa $^{1}$

ORCID iD: $\underline{0000-0002-8774-9633}$

Anna Regina Lanner de Moura ${ }^{2}$

ORCID iD: 0000-0003-3595-2151

\begin{abstract}
RESUMO
A pesquisa que tratamos neste artigo teve por objetivo analisar os conhecimentos e as dificuldades que alunos do curso de Engenharia Civil manifestaram em relação aos conteúdos básicos de Estatística através de uma avaliação diagnóstica. A pesquisa foi realizada com 30 (trinta) estudantes que cursavam o $5^{\circ}$ período do curso em uma universidade particular na cidade de São Luís/MA. Trata-se de uma pesquisa de natureza qualitativa de cunho interpretativo. Os resultados revelaram que os alunos apresentaram dificuldades em analisar e interpretar tabelas e gráficos, assim como em calcular as medidas de tendência central, principalmente a mediana. Apesar de a maioria ter acertado o cálculo da média aritmética e da moda, ainda assim houve uma quantidade expressiva de erros. A prova diagnóstica mostrou que as dificuldades dos alunos residem no desconhecimento conceitual, particularmente, da moda e da mediana, não sabendo quando aplicar uma e outra. Desse modo, esses resultados da prova podem servir de sustentação para um planejamento coerente às necessidades conceituais dos alunos, $o$ que poderá contribuir para uma aprendizagem mais efetiva desses conceitos estatísticos.
\end{abstract}

Palavras-chave: Conhecimentos. Dificuldades. Avaliação Diagnóstica. Estatística.

\begin{abstract}
The research in the present paper aimed to analyze knowledge and difficulties that Civil Engineering students expressed regarding basic contents of Statistics in a diagnostic evaluation. The research was conducted with 30 (thirty) students of 5th year at a private university in the city of São Luís/MA. It is a qualitative research of interpretative nature. Results show that the students had difficulties to analyze an interpret tables and graphics, as well as to calculate the measures of central tendency, mainly the median one. Despite most of them made the calculations of arithmetic average and mode correctly, there were still a great number of mistakes. The diagnostic test revealed that the students' difficulties are related to conceptual lack of knowledge, particularly of mode and median, since they do not know when to apply one or other. Therefore, those test results may be the sustaining of a coherent planning to the students' conceptual needs, which may contribute to more effective learning of those statistical concepts.
\end{abstract}

Keywords: Knowledge. Difficulties. Diagnostic Evaluation. Statistics.

\footnotetext{
${ }^{1}$ Doutor em Ensino de Ciências e Matemática pela Universidade Cruzeiro do Sul - UNICSUL. Professor e pesquisador do Instituto Estadual de Educação, Ciências e Tecnologia do Maranhão - IEMA e da Universidade Ceuma - UNICEUMA, São Luís, MA, Brasil. Endereço para correspondência: Av. Prof. Carlos Cunha, S/N Condomínio Pleno Residencial, apto 404, Torre Buriti, Jaracaty, São Luís, MA, Brasil. CEP: 65.076-820. E-mail: manolopromat@hotmail.com.

${ }^{2}$ Doutora em Educação pela Faculdade de Educação da Universidade Estadual de Campinas - UNICAMP. Pesquisadora da Universidade Ceuma - UNICEUMA, São Luís, MA, Brasil. Endereço para correspondência: Rua Corinto, 199 apto 181T, Vila Indiana, São Paulo, SP, Brasil. E-mail: lanner4@gmail.com.
} 


\section{INTRODUZINDO À TEMÁTICA}

Nas últimas décadas as discussões pedagógicas e de pesquisa (HAYDT, 2003; VASCONCELOS, 2008; LUCKESI, 2012; MASSETO, 2012) têm demonstrado a importância de se refletir sobre a avalição no processo educacional em todos os níveis de ensino, inclusive na Educação Superior. O ato de avaliar é uma das práticas mais antigas e consolidadas na cultura escolar; contudo, o processo avaliativo vem sempre acompanhado de dúvidas, angústias, incertezas e, até incoerências, pois constitui-se, não raro, de um processo traumático para quem está sendo avaliado. De acordo com Tyler (1974, apud HAYDT, 2003, p. 11), “o processo de avaliação consiste essencialmente em determinar em que medida os objetivos educacionais estão sendo realmente alcançados pelos programas do currículo e do ensino".

Quando se fala de avaliação no processo de ensino e aprendizagem, estamos referindonos à verificação do nível e da natureza da aprendizagem dos alunos, isto é, do que os alunos aprenderam. Neste estudo, o enfoque da avaliação será exatamente na aprendizagem, pois é justamente nessa área que são produzidos os efeitos mais marcantes dentro e fora do contexto das instituições educacionais, com repercussões de caráter ético, político e pedagógico. Baseado nessas considerações, o presente trabalho se propôs analisar os conhecimentos e as dificuldades que alunos do curso de Engenharia Civil manifestam em relação aos conteúdos básicos de Estatística através de uma avaliação diagnóstica e, a partir dessa avaliação, refletir sobre a importância da avaliação diagnóstica como instrumento norteador do processo ensino e aprendizagem na Educação Superior.

\section{REFERÊNCIAL TEÓRICO}

\subsection{Avaliação diagnóstica no contexto do ensino de Estatística}

A Educação Estatística, no Brasil, surgiu na década de 1970, mas o seu marco histórico ocorreu a partir da conferência internacional intitulada "Experiências e Expectativas do Ensino de Estatística: desafios para o século XXI”, realizada em 1999 pela Universidade Federal de Santa Catarina. Sua consolidação na Educação Básica iniciou-se com os Parâmetros Curriculares Nacionais - PCN (BRASIL, 1998) e se intensificou com a necessidade de desenvolver pesquisas que viessem sanar as dificuldades dos professores que ensinam conceitos e procedimentos estatísticos em todos os níveis educacionais, especialmente em cursos de nível superior (PAMPLONA, 2009). 
A Estatística constitui-se disciplina obrigatória nos diversos campos da Educação Superior, apresentando sua importância nas diversas áreas de conhecimento e, em particular, nos cursos das Ciências Exatas. Para esse nível de ensino, Wada (1996) define a Estatística como sendo disciplina de serviço, pois tem por objetivo instrumentalizar os usuários (profissionais) para que se faça uso adequado dessas ferramentas em sua área de atuação. As Engenharias, por exemplo, têm na Estatística uma importante ferramenta para estudo e análise de diversos fenômenos de interesse específico da formação profissional (CAMPOS; WODEWOTZKI; JACOBINI, 2011).

Uma classificação mais geral dos usos da Estatística é apresentada por Ignácio (2010). Segundo o autor, ela pode ser considerada tanto uma Ciência quanto um método e mesmo uma arte. Assume o status de Ciência quando, baseando-se em suas teorias, estuda grandes conjuntos de dados, independentemente da natureza destes. É considerada um método quando serve de instrumento para esclarecer fenômenos estudados por uma determinada Ciência (como na Agronomia, na Biologia, na Física, na Medicina ou na Psicologia). Finalmente, é considerada arte quando constrói modelos para representar a realidade.

De acordo com Lopes (2010), a Estatística auxilia a transformar dados brutos e de difícil compreensão em informações que expressam a realidade, mas para que isso ocorra, é preciso aprender seus conceitos básicos, tais como a organização dos dados em tabelas e/ou em gráficos e sobre a análise dos dados para a tomada de decisões. A autora ainda esclarece: "A estatística, com seus conceitos e métodos, configura-se como um duplo papel: permite compreender muitas das características da complexa sociedade atual, ao mesmo tempo em que facilita a tomada de decisões em um cotidiano onde a variabilidade e a incerteza estão sempre presentes” (p. 3).

A Estatística Descritiva compreende a coleta, a organização, a análise e a apresentação de dados procedentes de pesquisas de levantamento de dados de um fenômeno. Para representar essas informações, são utilizados gráficos e tabelas. Neste ramo da Estatística, enquadram-se, também, as medidas numéricas, entre elas as medidas de tendência central ou de posição. São elas: a média aritmética, moda e mediana. Dentre essas medidas de posição, a média aritmética é a mais utilizada em função de suas propriedades matemáticas (MATOS; KONRATH; AZAMBUJA, 2017).

Nesse sentido, a Base Nacional Comum Curricular - BNCC (BRASIL, 2017) indica a importância da Estatística na escola, a partir dos anos iniciais do Ensino Fundamental. De acordo com o documento: 
[...] todos os cidadãos precisam desenvolver habilidades para coletar, organizar, representar, interpretar e analisar dados em uma variedade de contextos, de maneira a fazer julgamentos bem fundamentados e tomar as decisões adequadas (BRASIL, 2017, p. 230).

Guerra e Bisognin (2016) ressaltam que, apesar de fazer parte do currículo da Educação Básica no Brasil, a Estatística ainda se encontra distante do cotidiano escolar, sendo pouco explorada em sala de aula, mesmo tendo uma grande importância no dia a dia dos alunos.

Conforme já discorrido, existe preocupação por parte dos pesquisadores com a formação estatística dos estudantes, principalmente os da Educação Superior que, na maioria das vezes, chegam com dificuldades conceituais básicas com relação à temática. Isto se deve, dentre outras causas, aos entraves para a efetivação do estudo da Estatística e da Probabilidade na Educação Básica (WALICHINSKI; SANTOS JUNIOR, 2013). Por essa razão, faz-se necessária, na Educação Superior, no início de cada período letivo, a realização de uma avaliação para que se possam obter informações sobre determinados conteúdos e, desta forma, fazer uma análise sobre a realidade da aprendizagem, ou seja, sobre a realidade do que os alunos já estudaram e aprenderam, e, a partir daí, (re)estruturar o plano de ensino com relação aos conceitos que serão discutidos em sala de aula.

A avaliação, de acordo com a literatura (HAYDT, 2003; SANTOS, 2005) apresenta três funções: (1) diagnosticar (investigar); (2) controlar (acompanhar) e (3) classificar (valorar). Relacionadas a essas três funções, existem três modalidades de avaliação: diagnóstica, formativa e somativa. Dentre essas três funções, a última é usada com maior frequência no âmbito escolar.

Na presente pesquisa, estamo-nos referindo à avaliação diagnóstica, um tema complexo e dinâmico, que se encontra no processo educacional, desde a chegada da atual Lei de Diretrizes e Bases da Educação Nacional - LDBEN (BRASIL, 1996). Contudo, foi com a dinâmica global que se deu sua importância no âmbito educacional, pois permite indicar qual a melhor estrutura curricular em qualquer nível de ensino.

Esse tipo de avaliação conduz a um diagnóstico da realidade que se pretende examinar, fornecendo informações prévias acerca dos aspectos enfocados. De acordo com Ferreira (2009), a avaliação diagnóstica pode ser utilizada para conhecer o aluno; identificar possíveis dificuldades de aprendizagem; verificar o que ele aprendeu ou não aprendeu; identificar causas de não aprendizagem; caracterizar o aluno quanto a interesses ou necessidades; caracterizar seus conhecimentos iniciais a respeito do conteúdo a ser tratado e replanejar o trabalho 


\section{CONTEXTO E CAMINHOS METODOLÓGICOS DA PESQUISA}

A presente pesquisa foi realizada com 30 (trinta) alunos do $5^{\circ}$ período do curso de Engenharia Civil de uma universidade particular, na cidade de São Luís, Estado do Maranhão, os quais foram identificados como $\mathrm{AEC} 1, \mathrm{AEC} 2, \mathrm{AEC} 3, \ldots \mathrm{AEC} 30$, de forma a facilitar a análise descritiva dos dados, assim como preservar-lhes as identidades.

Os dados foram coletados mediante uma avaliação diagnóstica realizada na primeira semana de aula, no primeiro semestre de 2019, pelo primeiro pesquisador que, à época, era professor dos alunos participantes. Trata-se de um estudo de natureza qualitativa, pois os procedimentos de análise baseiam-se na interpretação das imagens (protocolos) das respostas elaboradas pelos alunos, na tentativa de esclarecer a natureza e o significado das resoluções apresentadas por eles às questões. Além disso, o pesquisador colocou-se em contato direto com o ambiente da pesquisa, com os sujeitos envolvidos e com a atividade desenvolvida, tornandose, assim, o principal agente responsável pela organização e encaminhamento da avaliação (LÜDKE; ANDRÉ, 2017).

\section{DESCRIÇÃO E ANÁLISE DOS DADOS}

Aplicamos uma avaliação diagnóstica com a finalidade de analisar os conhecimentos e as dificuldades manifestados por alunos do curso de Engenharia Civil em relação aos conteúdos básicos de Estatística. Para análise foram consideradas as respostas escritas apresentadas pelos alunos nos protocolos correspondentes a cada questão que serão apresentados a seguir:

Uma das questões apresentadas na avaliação diagnóstica tinha por objetivo ler e interpretar uma tabela e um gráfico.

Os países em desenvolvimento fazem grandes esforços para promover a inclusão digital, ou seja, o acesso, por parte de seus cidadãos, às tecnologias da era da informação. Um dos indicadores empregados é o número de hosts, isto é, o número de computadores que estão conectados à internet. A tabela e o gráfico abaixo mostram a evolução do número de hosts nos três países que lideram o setor na América Latina.

\begin{tabular}{c|c|c|r|r|r}
\multicolumn{7}{c}{ Número de hosts } \\
\hline País & 2000 & 2001 & \multicolumn{1}{c}{2002} & \multicolumn{1}{c}{2003} & \multicolumn{1}{c}{2004} \\
\hline Brasil & 446.444 & 876.596 & 1.644 .575 & 2.237 .527 & 3.163 .349 \\
\hline México & 404.873 & 559.165 & 918.288 & 1.107 .795 & 1.333 .406 \\
\hline Argentina & 142.470 & 270.275 & 465.359 & 495.920 & 742.358 \\
\hline
\end{tabular}




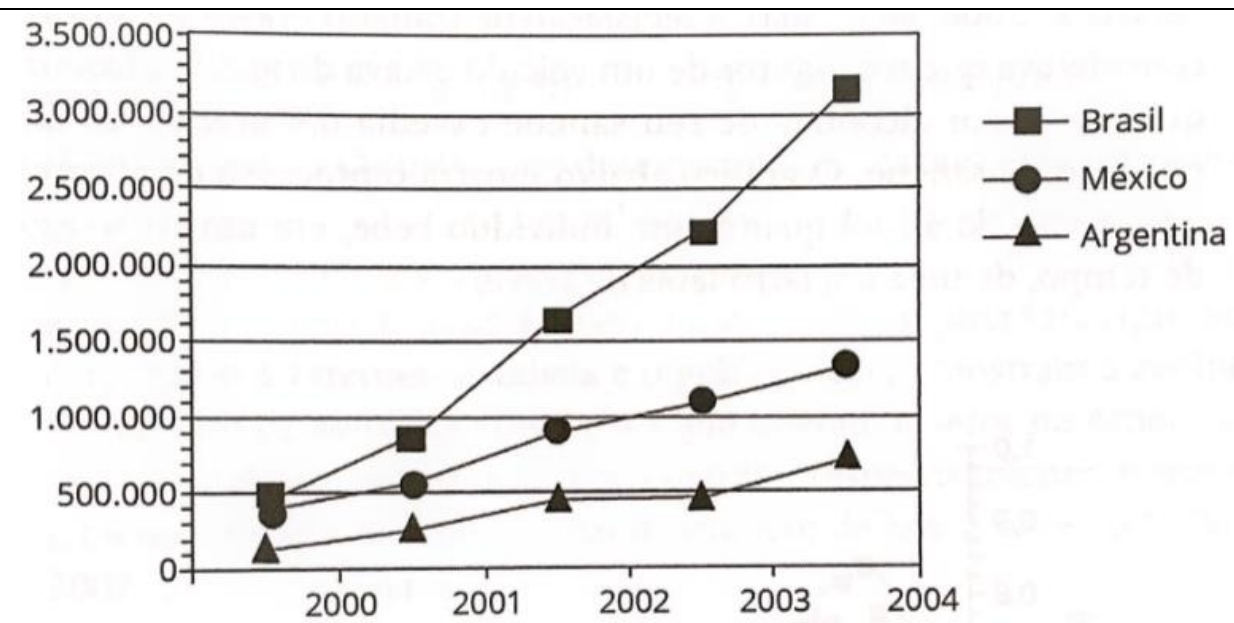

Dos três países, os que apresentaram, respectivamente, o maior e o menor crescimento percentual no número de hosts no período 2000-2004 foram:
a) Brasil e México.
b) Brasil e Argentina.
c) Argentina e México.
d) Argentina e Brasil.

e) México e Argentina

Fonte: Adaptação de Matos; Konrath e Azambuja (2017)

Analisando-se a questão, é possível perceber que os países que apresentaram, respectivamente o maior e o menor crescimento percentual foram o Brasil e o México (alternativa A). As repostas apresentadas pelos 30 estudantes, para essa questão, estão a seguir:

\begin{tabular}{|c|c|c|c|c|}
\hline A & B & C & D & E \\
\hline 10 & 19 & 1 & 0 & 0 \\
\hline
\end{tabular}

Quadro 1 - Números de acertos na $1^{\mathrm{a}}$ questão Fonte: Dados da pesquisa.

Podemos perceber, pelas respostas apresentadas no quadro 1, que a maioria dos alunos errou a questão. Apenas 10 acertaram a análise solicitada. Os alunos AEC27 e AEC12 que acertaram a questão justificaram suas respostas através da realização de cálculos, usando os dados da tabela, conforme segue:

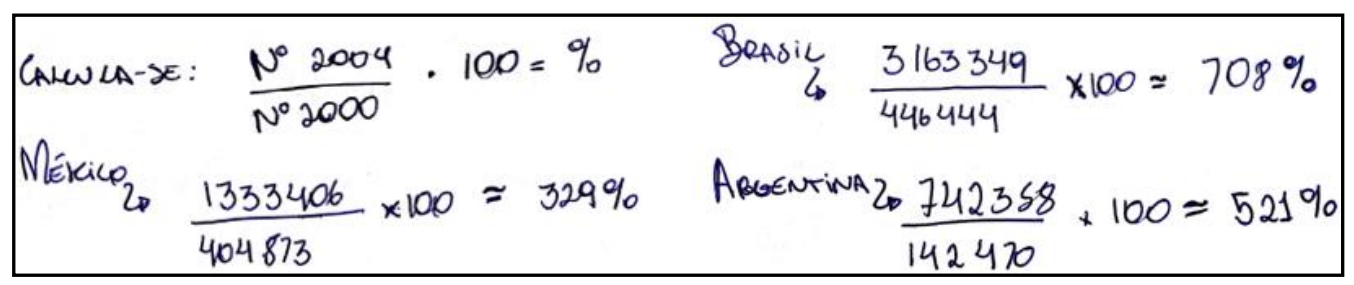

Figura 1 - Resposta apresentada por AEC27

Fonte: Dados da pesquisa. 


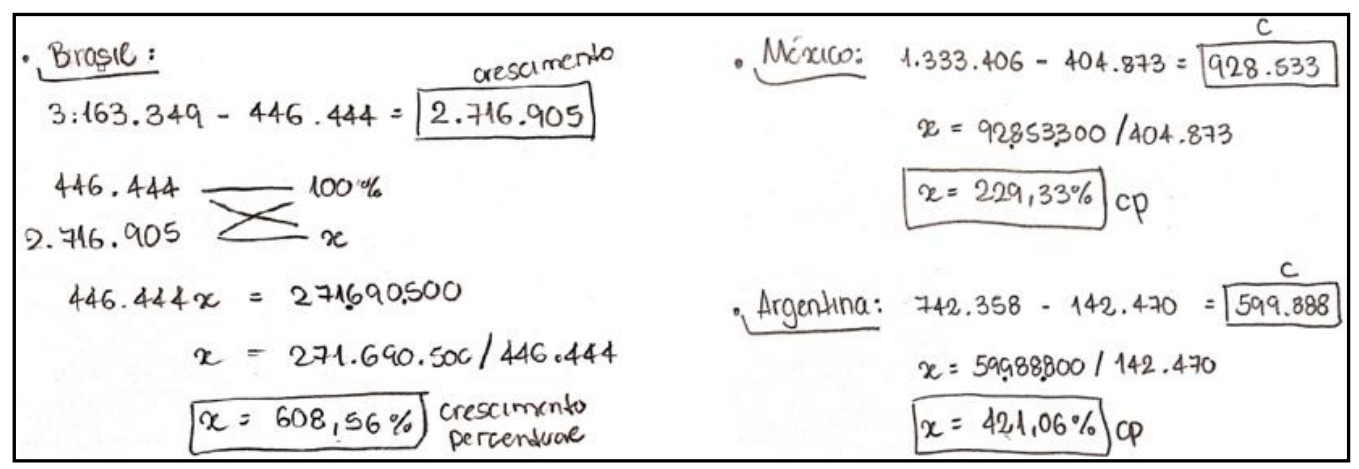

Figura 2 - Resposta apresentada por AEC12

Fonte: Dados da pesquisa.

Os alunos AEC1 e AEC23 que erraram a questão, marcando a alternativa B (Brasil e Argentina), apresentaram as seguintes justificativas:

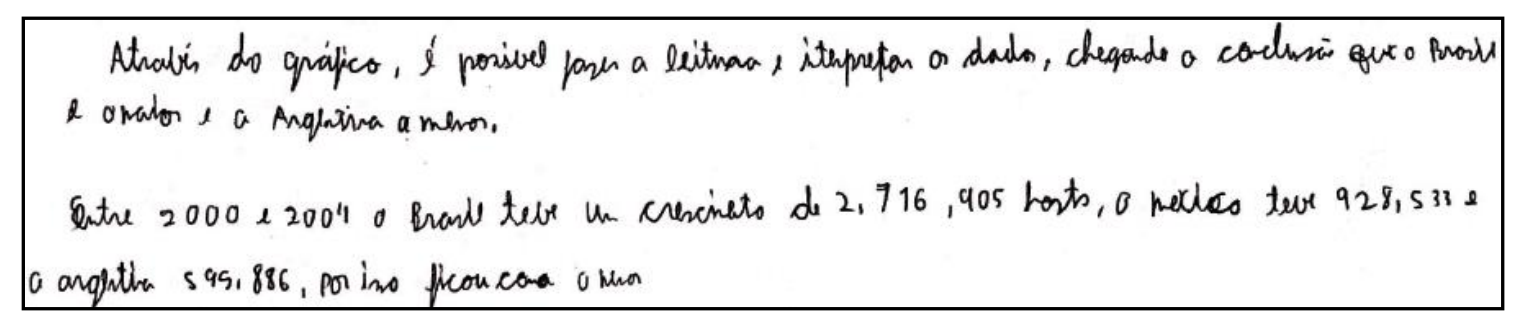

Figura 3 - Resposta apresentada por AEC1

Fonte: Dados da pesquisa.

O único aluno, que marcou a alternativa C (Argentina e México), justificou-a assim:

Pois foi feita amedia aritumetica, somando-se os
Cinco sados $E$ Divisisos por cinco.

Figura 4 - Resposta apresentada por AEC23

Fonte: Dados da pesquisa.

É possível ressaltar que os dois alunos que acertaram a questão realizaram o cálculo percentual utilizando os valores descritos na tabela, podendo assim comparar os valores percentuais de crescimento de cada país. Já os dois alunos que erraram pautaram-se numa análise qualitativa do crescimento, um deles apoiado na interpretação do gráfico.

Vale destacar que um dos objetivos da Estatística é apresentar de forma resumida os valores que uma ou várias variáveis podem assumir para que se tenha uma visão geral da variação de uma ou de mais variáveis.

Nesse sentido, as tabelas e os gráficos se apresentam como um dos recursos bastante utilizados para organização e apresentação de dados. Com eles, podemos visualizar muitas informações em um pequeno espaço, o que facilita a leitura, a interpretação e compreensão de fenômenos para se chegar a um resultado e tirar conclusões. Ou seja, tabelas e gráficos ajudam a descrever as informações com o intuito de proporcionar ao leitor uma visão mais rápida e 
ampla do evento em estudo. Além disso, construção, leitura e interpretação de tabelas e gráficos são importantes para o desenvolvimento do pensamento estatístico dos alunos. É conveniente, então, que o professor desenvolva uma abordagem que privilegie os métodos, as técnicas, os conceitos e os recursos estatísticos de forma articulada, como indicado por Campos, Wodewotzki e Jacobini, (2011).

Para que haja essa articulação, a questão 2 recomenda que o professor desenvolva com seus alunos uma prática docente, que trabalhe com dados relevantes obtidos pelos próprios alunos. Não é possível esgotar todos os assuntos relacionados aos conteúdos da Estatística em sala de aula. É importante, portanto, que o professor incentive seus alunos a irem a campo e coletar dados para que possam desenvolver de modo significativo as ideias conceituais que possibilitam a interpretação estatística. Ao trabalhar com os próprios dados, organizando-os em tabelas e gráficos, entram em contato com uma grande quantidade de informações.

A segunda questão, apresentada na avaliação, teve o objetivo de verificar se os alunos sabiam ou não calcular a média aritmética, a moda e a mediana de um conjunto de dados, foi a seguinte:

Em novembro de 2011, foi desenvolvido um estudo com o objetivo de avaliar o fluxo de veículos motorizados que passam na Avenida Rio Grande, localizada na praia do Cassino. Em um dos horários em que foi feito monitoramento, entre $18 \mathrm{~h}$ e $18 \mathrm{~h}$ 15min, do dia 09/11/2011, foram encontrados os seguintes resultados para veículos/minutos: $14 ; 9 ; 10 ; 8 ; 7 ; 8 ; 9 ; 12 ; 10$; $7 ; 10 ; 11 ; 8 ; 6$ e 10. Com base nas informações, encontre a média aritmética, a moda, e a mediana.

Fonte: Matos, Konrath e Azambuja, (2017).

Analisando-se o conjunto de dados e realizando-se os cálculos corretamente, quando necessário, os alunos deveriam encontrar os seguintes resultados: média de 9,27 veículos por minuto; moda de 10 veículos por minuto; e mediana de 9 veículos por minuto.

O número de acertos, erros e questões "não respondida" encontra-se no quadro 2 a seguir:

\begin{tabular}{|c|c|c|c|c|c|c|c|c|}
\hline \multicolumn{4}{|c|}{ média aritmética } & \multicolumn{3}{c|}{ moda } & \multicolumn{3}{c|}{ mediana } \\
\hline acertos & erros & NR & acertos & erros & NR & acertos & erros & NR \\
\hline 25 & 4 & 1 & 20 & 7 & 3 & 5 & 16 & 9 \\
\hline
\end{tabular}

Quadro 2 - Números de acertos, erros e não respondidas na $2^{\mathrm{a}}$ questão Fonte: Dados da pesquisa.

Observando-se o quadro, percebe-se que a média é a medida numérica mais conhecida pelos alunos que participaram da pesquisa, pois foi a que teve maior número de acertos. 
Entretanto, essa medida numérica precisa ser melhor discutida em sala de aula, pois, de acordo com Mattos, Konrath e Azambuja (2017), ela poderá apresentar uma concepção mais ampla e detalhada, como é o caso da média ponderada.

Para calcular a média aritmética, os alunos que acertaram a questão usaram o mesmo procedimento, a não ser pelo fato de alguns, além de apresentar o raciocínio quantitativo (que envolve algoritmos numéricos), expuseram, também, o raciocínio qualitativo (explicação das estratégias utilizadas na resolução), conforme indicado nos protocolos a seguir:

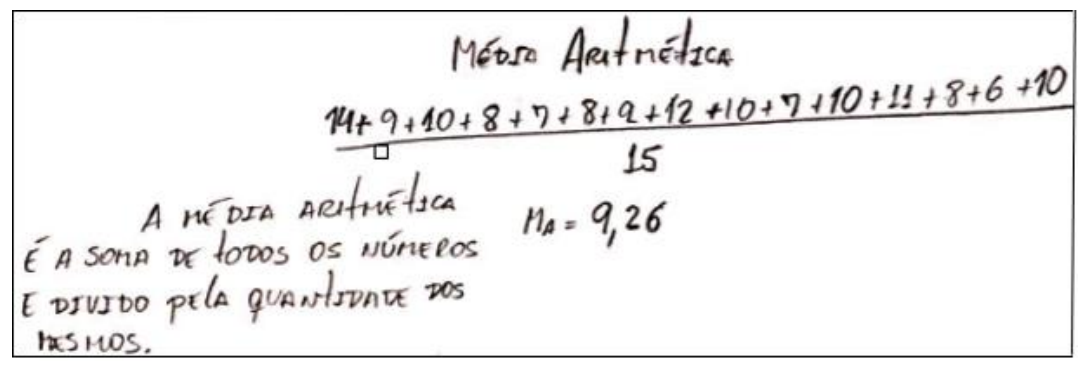

Figura 5 - Respostas apresentadas por AEC20

Fonte: Dados da pesquisa.

Dos quatro alunos que erraram a questão, um (AEC17) apresentou como resposta a explicação de que a média aritmética seria entre 9 e 10 carros por minuto, não expondo, porém, os cálculos; os outros três fizeram a somatória dos dados de forma correta, contudo, erraram no cálculo da divisão, como mostra o protocolo:

$$
\frac{14+9+10+8+7+58+9+12+10+7+10+11+8+6+10}{14}=9,93
$$

Figura 6 - Resposta apresentada por AEC29

Fonte: Dados da pesquisa.

Apesar de a maioria dos alunos ter acertado o cálculo da média aritmética, não é garantido que tenham a compreensão de que esta representa a medida de tendência central que resume os dados e que permite a análise da variação desses dados. Este é um indicador da avaliação diagnóstica para que o professor inclua, em seu planejamento, um desenvolvimento conceitual da média aritmética mais ampliado e aprofundado daquele que costuma abordar em sala de aula.

A maioria dos alunos não encontrou dificuldade para identificar o número modal no conjunto de dados. A respeito disto, as respostas e justificativas apresentadas por eles foram semelhantes a do protocolo que segue: 


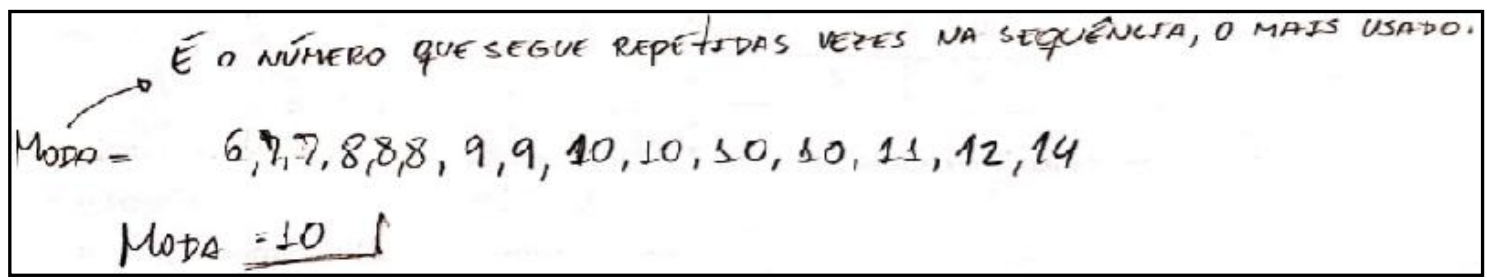

Figura 7 - Resposta apresentada por AEC20

Fonte: Dados da pesquisa.

Com relação à mediana, as respostas foram bem diversificadas. Somente cinco alunos acertaram esse item; os demais erraram ou não responderam, conforme pode ser observado no quadro 2.

Dos alunos que acertaram, algumas respostas foram:

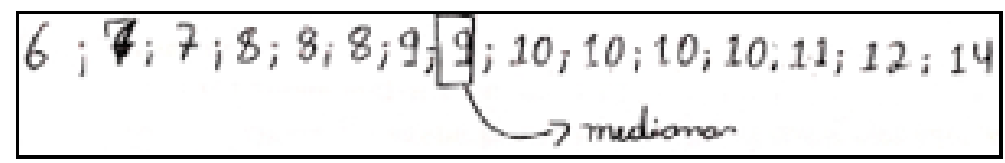

Figura 8 - Resposta apresentada por AEC28

Fonte: Dados da pesquisa.

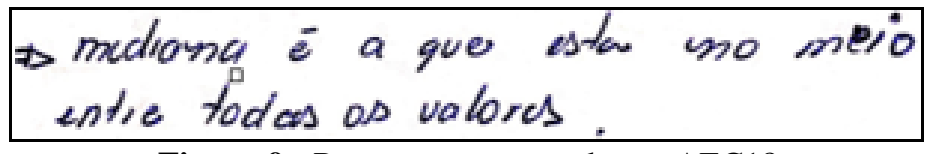

Figura 9 - Resposta apresentada por AEC18

Fonte: Dados da pesquisa.

As respostas apresentadas pelos alunos AEC28 e AEC18 indicam que eles entenderam que a mediana é a medida que divide a distribuição dos dados em duas partes cada uma com o mesmo número de elementos. No entanto, é importante pontuar para os alunos que a mediana é o segundo quartil mais utilizado na análise dos dados, por se tratar de uma medida de tendência central em que 50\% dos valores são menores ou iguais a ela.

Alguns dos que erraram esse item informaram que a mediana da sequência é 12, conforme protocolo a seguir:

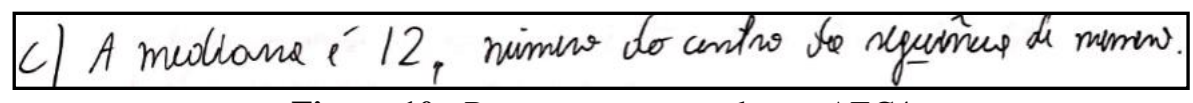

Figura 10 - Resposta apresentada por AEC4

Fonte: Dados da pesquisa.

Houve quem respondeu que a mediana seria a soma do primeiro e do segundo termo, dividida por 2, ou seja, a média entre os valores dos dois termos; e também, quem respondeu que a mediana seria 9,5 , conforme podemos observar nos protocolos a seguir: 


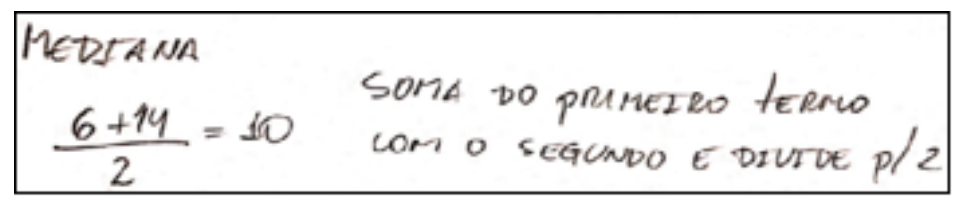

Figura 11 - Respostas apresentadas, respectivamente, por AEC20 e AEC19

Fonte: Dados da pesquisa.

Os erros cometidos pelos alunos, em relação a essas três medidas numéricas, apontam para a necessidade de o professor incluir em seu planejamento um tratamento conceitual desse conteúdo, pois é importante também, compreender quando cada uma delas deve ser aplicada e como devem ser interpretados seus resultados. Isto é, saber escolher qual delas atende melhor ao que se precisa saber ou ao tratamento que se quer dar aos dados de um fenômeno. Além disso, essas medidas se tornam relevantes quando pensamos no baixo nível de complexidade para sua determinação quanto às ferramentas matemáticas necessárias (MATTOS; KONRATH; AZAMBUJA, 2017).

\section{CONSIDERAÇÕES}

Os resultados da pesquisa mostram que o objetivo foi alcançado. A avaliação diagnóstica permitiu esclarecer que os alunos que participaram da pesquisa apresentam dificuldades em analisar e interpretar tabelas e gráficos. Com relação às medidas de tendência central, a pesquisa aponta que, apesar de a maioria dos alunos ter acertado o cálculo da média aritmética e da moda, ainda assim houve um número expressivo de erros nessas duas medidas. Em relação à mediana, eles expressaram dificuldades em aplicar essa medida nos dados do problema proposto. De fato, pouquíssimos alunos acertaram esse item. Os conteúdos da Estatística são pouco aprofundados na Educação Básica ou, até, não são abordados, de modo a ser previsível o desconhecimento desses conteúdos que o estudante da Educação Superior apresentará nas disciplinas que os exigem. Sendo assim, os resultados da presente pesquisa sugerem a importância da avaliação diagnóstica para a orientação do planejamento dos conteúdos estatísticos de modo a atender às dificuldades conceituais que possam residir nesses estudantes. Da mesma forma, indica para o professor os conteúdos que precisam ser revistos e que necessitam de um tratamento conceitual mais aprofundado, como no caso desta pesquisa. Ele se fez presente nas respostas da maioria dos alunos quanto à necessidade de um desenvolvimento conceitual mais preciso das três medidas numéricas, média, moda e mediana. Pois saber calculá-las é relevante para dar continuação ao estudo dos outros conceitos e 
conteúdos estatísticos. Embora não seja suficiente, no entanto, é necessário que se compreenda quando cada uma dessas medidas deve ser aplicada e como interpretar seus resultados.

A pesquisa sugere que as informações obtidas por este instrumento avaliativo são de suma importância para o professor organizar sua prática pedagógica com vistas a obter maior sucesso na aprendizagem do que obtém ao desenvolver os conteúdos sem a visão das verdadeiras necessidades conceituais dos alunos. Os resultados da avaliação diagnóstica podem auxiliá-lo a repensar e inovar sua prática instituída (re)organizando-a em um planejamento mais consistente conceitualmente e coerente com as necessidades dos alunos.

\section{REFERÊNCIAS}

BRASIL. Ministério de Educação e Cultura. Lei de Diretrizes e Bases da Educação Nacional - Lei no 9394/96, de 20 de dezembro de 1996. Estabelece as diretrizes e bases da Educação Nacional. Brasília: MEC, 1996. Disponível em: https://www.planalto.gov.br/ccivil_03/Leis/L9394.htm. Acesso em: 18 mai. 2019.

BRASIL. Ministério da Educação e Cultura. Secretaria de Educação. Parâmetros Curriculares Nacionais: Matemática $1^{\circ}$ e $2^{\circ}$ ciclos - Brasília: MEC, 1998. Disponível em: http://portal.mec.gov.br > seb > arquivos > pdf > livro03. Acesso em: 25 mar. 2018.

BRASIL. Ministério da Educação e do Desporto. Base Nacional Comum Curricular BNCC. 3. versão. Brasília: MEC, 2017. Disponível em: http://basenacionalcomum.mec.gov.br/. Acesso em: 06 jun. 2019.

CAMPOS, C. R.; WODEWOTZKI, M. L. L.; JACOBINI, O. R. Educação Estatística: teoria e prática em ambientes de modelagem matemática. Belo Horizonte: Autêntica Editora, 2011.

FERREIRA, L. M. S. Retratos da avaliação: conflitos, desvirtuamentos e caminhos para a superação. 3. ed.- Porto Alegre: Mediação, 2009.

GUERRA, S. H. R.; BISOGNIN, V. Investigação matemática na sala de aula: ensino de conceitos de estatística para o 8..$^{\circ}$ ano do ensino fundamental. Vidya Revista Eletrônica. Santa Maria, v. 36, n. 2, p. 275-295, 2016. Disponível em: https://periodicos.ufn.edu.br/index.php/VIDYA/issue/view/158. Acesso em: 15 out. 2017.

HAYDT. R. C. Avaliação do Processo Ensino-Aprendizagem. 6. ed. - São Paulo: Editora Ática, 2003.

IGNÁCIO, S. A Importância da estatística para o processo de conhecimento e tomada de decisão. Nota Técnica Ipardes, Curitiba, n. 6, out. 2010. Disponível em:

http://www.ipardes.pr.gov.br/Pagina/Publicacoes-NT-2010. Acesso em: 12 set. 2018.

LOPES, C. E. Os desafios para Educação Estatística no currículo de Matemática. In: LOPES, C. E; COUTINHO, C. Q. S.; ALMOULOUD, S. A. (Org.). Estudos e reflexões em Educação Estatística. Campinas: Mercado de Letras, 2010, p. 47-64. 
LÜDKE, M.; ANDRÉ, M. E. D. A. Pesquisa em educação: abordagens qualitativas. 2. ed. [Reimpr.]. - Rio de Janeiro: E.P.U, 2017.

LUCKESI, C. C. Avaliação da aprendizagem escolar: estudos e proposições, 22. ed. -São Paulo: Cortez Editora, 2012.

MASETTO, M. T. Competência Pedagógica do Professor Universitário, 2. ed. rev. - São Paulo, Summus, 2012.

MATTOS, V. L. D.; KONRATH, A. C.; AZAMBUJA, A. M. V. Introdução à estatística: aplicações em ciência exatas. 1. ed. - Rio de Janeiro: LCT, 2017.

PAMPLONA, A. S. A formação estatística e pedagógica do professor de matemática em comunidades de prática. 2009, 267 f. Tese (Doutorado em Educação Matemática) Faculdade de Educação - Universidade Estadual de Campinas, Campinas-SP. 2009.

SANTOS, C. R. Avaliação Educacional: análises conceitual, legal e crítica. In: SANTOS, C. R.; FERREIRA, M. C. I. (Org.). Avaliação educacional: um olhar reflexivo sobre a prática. São Paulo: Editora Avercamp, 2005, p. 21-44.

VASCONCELLOS, C. S. Avaliação: concepção dialética libertadora do processo de avaliação escolar. 18. ed. - São Paulo: Libertad, 2008.

WADA, R. S. Estatística e Ensino: um estudo sobre representações de professores de $3^{\circ}$ grau. 1996. Tese (Doutorado em Educação) Faculdade de Educação - Universidade Estadual de Campinas, Campinas-SP, 1996.

WALICHINSKI, D.; SANTOS JUNIOR, G. Educação estatística: objetivos, perspectivas e dificuldades. Revista Imagens da Educação, Maringá, v. 3, n. 3, p. 31-37, 2013. Disponível em: http://periodicos.uem.br/ojs/index.php/ImagensEduc/issue/view/848. Acesso em: 23 nov. 2015.

Submetido em: 09 de novembro de 2019.

Aprovado em: 28 de janeiro de 2020. 